\title{
When HTA is confidential and experts have no power: the case of Hungary
}

Marcell Csanádi, University of Pecs, Hungary / Syreon Research Institute, Budapest, Hungary

Olga Löblová, Central European University, Budapest, Hungary

Piotr Ozierański, University of Bath, UK

András Harsányi, Eötvös Loránd University, Budapest / National Health Insurance

Fund of Hungary

Zoltán Kaló, Eötvös Loránd University, Budapest / Syreon Research Institute, Budapest, Hungary

Martin McKee, London School of Hygiene and Tropical Medicine, UK Lawrence King, University of Cambridge, UK 


\title{
When HTA is confidential and experts have no power: the case of Hungary
}

\begin{abstract}
Health technology assessment (HTA) is not simply a mechanistic technical exercise as it takes place within a specific institutional context. Yet, we know little about how this context influences the operation of HTA and its ability to influence policy and practice. We seek to demonstrate the importance of considering institutional context, using a case study of Hungary, a country that has pioneered HTA in Central and Eastern Europe. We conducted 26 in-depth, semi-structured interviews with public and private sector stakeholders. We found that while the HTA Department, the Hungarian HTA organisation, fulfilled its formal role envisaged in the legislation, its potential for supporting evidence-based decision-making was not fully realised given the low levels of transparency and stakeholder engagement. Further, the Department's practical influence throughout the reimbursement process was perceived as being constrained by the payer and policymakers, as well as its own limited organisational capacity. There was also scepticism as to whether the current operational form of the HTA process delivered "good value for money". Nevertheless, it still had a positive impact on the development of a broader institutional HTA infrastructure in Hungary. Our findings highlight the importance of considering institutional context in analysing the HTA function within health systems.
\end{abstract}




\section{Introduction}

Health technology assessment (HTA) supports decision-makers in allocating scarce resources for expensive medical technologies, primarily pharmaceuticals (Banta 2003; Henshall et al. 1997; Valesco-Garrido and Busse 2005). It offers particular opportunities in settings such as Central and Eastern European (CEE) countries (Mandrik et al. 2015) that face significant budgetary constraints and where suboptimal investment decisions bring substantial opportunity costs (Kolasa et al. 2016). The potential benefits of HTA include more rational use of resources, improved patient outcomes resulting from greater use of evidence-based technologies (Schumacher and Zechmeister 2013; Zechmeister and Schumacher 2012), and more generally, by contributing to a climate that values evidence in healthcare policy and practice (Oortwijn et al. 2008). Yet, these benefits may not always be achieved in practice. The few studies that have examined the institutional characteristics and context of HTA have reached conflicting conclusions (Fischer et al. 2013; Böhm et al. 2014) so any effects of different institutional contexts on HTA processes are far from clear (Landwehr and Boehm 2011) and recommendations on best practices in HTA implementation are difficult to generalise (Kaló et al. 2016).

Hungary was among the pioneers of HTA in Central and Eastern Europe (Löblová 2016). In this paper, we examine the institutional arrangements within which HTA in Hungary takes place, its influence on decision-making, and how its benefits and costs are viewed by key stakeholders. While the precise arrangements that exist in Hungary are unique to the country, we offer this paper as an example of the importance of understanding the HTA function within a broader context, and in doing so, hope that it will provide lessons for other countries seeking to implement or strengthen their own HTA systems.

The development of HTA in Hungary and its institutional basis have been described in detail elsewhere (Gulacsi et al., 2004; Boncz et al., 2006; Kaló et al., 2013; Gulácsi and Péntek, 2014). Moreover, there have been detailed studies of particular elements of the process, including the continuing development of methodological guidelines for economic evaluations (Szende et al. 2002; Gulácsi et al. 2014), the 
application of multi-criteria decision-making in assessing technologies (Endrei et al. 2014), and developing a critical appraisal checklist (Inotai et al. 2012). However, we still lack an adequate understanding of many aspects of how HTA and its process of making decisions on reimbursement actually operate, in part because of a lack of basic documentation in the public domain. Notably, while previous studies suggest the existence of informal rules and practices that may complement or circumvent the formal reimbursement process, these have not been subjected to in-depth scrutiny. Consequently, we know very little about the role and influence of key stakeholders, including the public HTA body, in final reimbursement decisions. Nor has the existing literature sought to identify the benefits and costs associated with the existing model of HTA in Hungary.

The aim of this paper is therefore threefold. First, to identify institutional characteristics of HTA that may either facilitate or constrain the decision-supporting role of the HTA Department. Second, to assess the influence of the HTA Department in relation to other key players engaged in the reimbursement process. Third, to determine whether various stakeholders consider the current HTA system to represent good "value for money" and how they perceive its costs and benefits.

In the next section, we provide a brief overview of the Hungarian reimbursement system. We then explain our methods. In the remainder of the paper we answer each of the three research questions in turn. We conclude that Hungarian HTA has faced challenges in adapting to changing circumstances and suggest reasons why this may be so.

\section{Overview of the current Hungarian reimbursement and HTA procedures}

Hungary established its own HTA Department, an organisation tasked with reviewing proposals for reimbursement of health technologies, in 2004 . It had just acceded to the European Union (EU) and this was means of complying with the EU's Transparency Directive (Gulácsi et al. 2009; Kolasa et al. 2012). Since its inception the HTA Department has moved among various organisational structures and 
currently lies within the National Institute of Pharmacy and Nutrition (NIPN), a licensing authority for pharmaceutical and public administrational matters.

The HTA department is part of a broader process of reimbursing new medical technologies. In line with Ministerial Decree No. 32/2004. (IV. 26.), any manufacturer seeking reimbursement of a new pharmaceutical or a price increase or new indication for one already on the market must submit a full HTA dossier. The most common "normal" reimbursement procedure starts with the submission of a reimbursement application to the National Health Insurance Fund (NHIF). The application is then passed to the HTA Department and the relevant College of Medical Professionals. These bodies are responsible for, respectively, conducting a critical appraisal of the submission, and providing an expert opinion on the technology. The reimbursement procedures are coordinated by the Department of Reimbursement (DR) at the NHIF, which also prepares a preliminary opinion on the submission.

The critical appraisal document, the medical expert opinion, and the preliminary opinion of the DR are discussed by the Health Technology Assessment Committee (HTAC), based at NHIF. Approximately 10 people attend HTAC meetings but the precise mix may vary according to the technology being considered. There are usually 5-6 NHIF representatives, 2-3 medical professionals who are permanent members, representatives of the HTA Department and relevant advisors from the College of Medical Professionals. However, only NHIF representatives and the permanent medical professionals have voting rights. The HTAC makes a recommendation on reimbursement, either positive or negative, and decides the appropriate reimbursement scheme. The HTAC recommendation is reached by a simple majority vote among those with voting rights. Subsequently, the DR prepares a final recommendation for the Director-General of the NHIF. In some cases, the Director-General has the authority to make the final decision based on the recommendation of the $\mathrm{DR}$. However, in many cases a positive reimbursement decision requires changes in the legislation for reimbursing health technologies (Annexes of the Ministerial Decree No. 32/2004) for instance where a new indication is added. In such cases, the Ministry of Human Capacities, a super- 
ministry that includes the State Secretary of Health and the Ministry of National Economy are involved in the decision-making process.

\section{Methods}

We applied a single case study approach (Yin 2003) using qualitative data from 26 in-depth, semi-structured expert interviews with major stakeholders involved in HTA in Hungary. The interviews were conducted between August 2016 and January 2017 in Budapest. We applied purposive sampling, aiming to include key categories of stakeholders involved in the HTA procedures in Hungary, namely the HTA Department, the NIPN, the NHIF, the Ministry responsible for health (i.e. Ministry of Human Capacities), academia, manufacturers, consultant companies, and patient organisations (Table 1). The interviews were carried out by Researcher A (in Hungarian, 13 interviews in total), Researcher B (in English, 7 interviews) and Researcher D (in Hungarian, 6 interviews in total). All the interviewers had been involved in the study from the outset and are experienced in HTA in Hungary. The vast majority of interviews were conducted in person; only 4 interviews took place via Skype. A typical interview lasted around one hour.

$<$ Table 1 about here>

Potential interviewees were selected based on their current or previous institutional affiliations, their expert status evidenced by, for example, authoring scientific articles or participation in relevant conferences, or recommendations by other interviewees. The expert knowledge of our interviewees was also evidenced by their multiple prior affiliations. The interview guide was agreed on at the beginning of the fieldwork and comprised mainly broad open-ended questions. These questions asked the interviewees' opinions on the following topics:

- the most important benefits of HTA in Hungary

- potential benefits which cannot be achieved with the current HTA system

- key challenges facing the HTA process in Hungary

- is the system being fit for its purpose?

- transparency of procedures 
- costs associated with HTA in Hungary

Additionally, more detailed questions were also asked in subsequent interviews, drawing on emerging results. These concerned issues such as:

- movement of professionals between the private and public sector

- the market for HTA consultancies

- the quality of HTA dossiers

- the data availability for appraisals by the HTA Department

We encouraged interviewees to elaborate on their points in depth to maximise the value of their unique expert knowledge. With seven non-responses or refusals, we achieved a 79 percent response rate. Non-responses were distributed evenly across the key stakeholder categories, with the exception of medical professionals whom we were unable to reach. This was presumably because of their time pressured working conditions or a lack of awareness of HTA operation in the healthcare system.

Our research was approved by the Ethics Committee at the Department of Sociology at the University of Cambridge. All interviewees were briefed about the objectives of the study, the interview procedure, and our intention to analyse data and publish our findings. We reassured interviewees about our commitment to protecting their anonymity by creating broad interviewee categories. As an additional reassurance, we offered them the option of accepting or refusing tape recording. Six interviewees refused such a recording. In these cases, extensive notes were taken during and immediately after the interview.

For each interview, detailed interview protocols in English, omitting redundant material clearly irrelevant to our research, were prepared by Researcher A and Researcher $D$ based on recordings (where available) and extensive notes. The interview data were analysed by Researcher $A$ and then discussed with Researcher $B, C$ and $D$. Researcher $E, F$ and $G$ contributed to their interpretation. A thematic analysis (Guest et al. 2011), facilitated by NVivo 10, allowed an initial coding of the interviews based on concepts derived from the research questions. At a later stage, some codes were collapsed and code families and networks were established, to 
best reflect the main themes emerging from the data. We present quotations expressing views that were shared by the interviewees representing various stakeholder perspectives. The interviewer's ID number is given in square brackets. Since many of the interviews were recorded in Hungarian, they are paraphrased here in English. Where statements offered by the interviewees differ, we chose quotations that appeared the most appropriate in light of the entire dataset.

\section{Findings}

\subsection{The role of the HTA Department}

Our interviewees pointed to a number of areas in which the HTA Department successfully fulfilled its formal role of providing evidence for reimbursement decisions, as set out in the legislation. Appraisals undertaken by the HTA department were widely viewed as independent, and conducted according to predefined criteria. A high-ranking NHIF official stressed, "The HTA Department (...) is more like an independent group of experts to support the NHIF." [12] According to a former HTA Department senior official, "These [appraisal documents] have fiftysixty pages which is too much but it is a comprehensive description on efficiency and safety, health gain, and review [on] the health economic analysis, which includes the price of the product and the comparator. And at the end there is an opinion."[20] A further strength of the HTA Department was its timeliness in conducting appraisals. Interviewees typically reported that the Department normally achieves the preparation of an evaluation within the 45 day time-window. A consultancy company manager highlighted, "There is no such thing as having the submission on hold [at the HTA Department]."[10]

Nevertheless, some interviewees still saw the HTA Department's role in supporting evidence-based decision-making as suboptimal. Most notably, the assessments provided one-off snapshots in time - the HTA Department only contributed to the earliest phases of the reimbursement process, with unrealised potential for subsequent contributions. According to a former HTA Department employee, "[HTA Department] has only 45 days to assess the technology. So if something changes, for example new evidence comes out or the price is changed, the HTA Department is not 
involved anymore." [15] A drug company representative also noted the absence of a process to revise previous decisions: "the follow-up process is missing. This is an important limitation of the [reimbursement] system." [4]

The interviewees conceded that there was insufficient commitment of decisionmakers to publicly disclose information on technology assessment documents that would justify decisions on public reimbursement. An academic explained, "if there is no need for justification, implicit judgment becomes the most important part [in decision-making]. And those consultants who got the insights on how the implicit judgments are made become successful."[14] Although HTA experts, and even, occasionally, policymakers, publicly acknowledged the importance of transparency, concrete remedies were not put into practice. A senior HTA consultant explained: "actually in public no one is against it. The answer that people usually say is that they want do it [put HTA documents in the public domain] in the near future (...) but it just never happens."[15] An interviewed academic was emphatic on this point, "Unfortunately we were not brave enough to move into a direction where we can operate HTA in a transparent way. "[14]

This institutional shortcoming could be addressed in the future, as is being suggested in on-going consultations about possible publication of executive summaries from appraisals including major questions on elements from the submission (e.g. comparator, cost-effectiveness ratio etc.). A member of the HTA Department emphasised, "I don't want to be a part of a black box."[17] Yet the proposed improvements to transparency may face opposition from some stakeholders, including the manufacturers. A pharmaceutical company representative explained that more transparency could even be risky for manufacturers: "If an evaluation is negative by the HTA Department and then the NHIF still makes a positive recommendation, it would be immediately attacked by competitor companies. They would use these information against each other."[9]

A related area of unrealised potential arose from the limited extent of consultations with key stakeholders, especially clinicians, manufacturers, and patient 
organisations. According to a current HTA Department employee, "There is a need [for consultation with clinicians] and the HTA Department would like to have more support from external experts especially in the clinical part (...) There were no attempts [to formalise consultations] and also it is hard to motivate the busy physicians. This is not in the everyday practice."[24] This is the situation even though representatives from the Colleges of Medical Professionals also give their opinion at the HTAC. Moreover, former HTA Department employees explained that, "This [consultation with clinicians] is sub-optimal. There should be a well-regulated process of doing this" [15] and "Key opinion leaders are not really interested in HTA. They have a perception of HTA that it is a bureaucratic thing, shifting papers back and forth."[3] Similarly, manufacturers complained about the limited feedback on their submissions "A basic problem is that this process is not a consultation type process. There are no consultation opportunities to conduct a proper and objective evaluation of the submission." [9] This issue was recognised by those conducting assessments; negotiations are underway to create a platform for sharing health economic models to facilitate two-way discussion between the HTA Department and manufacturers. Unlike the situation in some other countries, patient organisations have no formal contact with the HTA Department. A representative of a patient organisation explained: "In general a Hungarian patient or a Hungarian patient organisation never hears about HTA. They are not aware of the process in which the HTA Department is involved. (...) On the other hand, (...) it is not facilitated to invite [patient organisations] to collaborate. This is not even on the agenda."[21]

\subsection{Influence of the HTA Department}

The influence of the HTA Department on reimbursement processes was widely viewed as limited. A former key governmental official emphasised, "The influence of HTA is smaller than it would be required. This is changing and there are steps forward but still it is smaller than required."[25] This point was summarised, perhaps most vividly, by a high-ranking government official, "The HTA Department works as an ante-room, where people wipe off their shoes."[19] 
Many of our interviewees stressed that the HTA Department had limited influence on the NHIF. A senior consultant stressed, "there is an ambivalent relationship between the NHIF and the HTA Department. (...) for the NHIF the technology assessment is too academic and requires that everything should be perfect."[10] A key issue was the narrow scope of appraisals, including only evaluations on the validity of data included in manufacturer submissions. According to a high-level governmental official, "they only review that an analysis is appropriate or not, in the context of the given methodology. This is too narrow a perspective."[19] Contrastingly, some interviewees felt that the HTA Department should be providing more direct advice to decision-makers. An academic explained, "The result of this kind of restriction, [is] that the opinion is usually quite neutral and you can interpret it in different ways. (...) But they never made a strong statement like 'the quality of the submission is extremely poor, extremely biased and there is no evidence on some point'."[14] Some of our interviewees also mentioned opaque phrasing of recommendations provided by the Department that were ill- suited to real-life decision-making purposes. An NHIF employee noted, "It is not helpful for instance when they say that the cost-effectiveness is uncertain." [12]

Even more important was the lack of inclusion of a NHIF institutional perspective in appraisals undertaken by the HTA Department. A former NHIF employee added, "The main weakness is that [HTA] does not serve the interest of the payer. Because it does not lead to better decisions. "[3] Specifically, the HTA Department does not prepare recommendations on whether a new technology should be reimbursed or not. This disjuncture of organisational perspectives could, in certain circumstances, lead to the by-passing of the HTA Department by the NHIF. This was particularly the case when the NHIF had enough knowledge about the technology, and the agreement with the manufacturer on price was seen as acceptable. In this case the NHIF saw the contribution from HTA as redundant. "Instead of a normal procedure it could be acceptable to have a simplified procedure," [12] was an assertion made by a high-ranking NHIF employee. Consequently, it appeared that in some cases emerging recommendations from the HTA Department were disregarded a priori. A former HTA Department employee stressed, "In some cases the final decision is 
made before the opinion [of the HTA Department] is discussed. (...) NHIF already has information whether the drug has a place in the therapeutic practice in Hungary or not."[20]

Yet another factor limiting the HTA Department's influence on the NHIF was its reliance on list prices as opposed to the actual, often discounted, prices negotiated with drug manufacturers. While the Hungarian system relies heavily on pricevolume agreements between the manufacturer and the NHIF, the HTA Department is not provided access to the details of any negotiations taking place in parallel to its appraisal process. An NHIF employee explained, "There is an information asymmetry between the HTA Department and the national payer [NHIF]. This is the result of the confidential prices which are set through national tendering or negotiation process in case of innovative products." [12] The HTA Department has no information regarding the state of negotiations on actual prices. According to a representative of a drug company, "From this point on the whole HTA system worth nothing. Manufacturers submit analyses which have completely wrong input data as price."[6] Similarly, a former HTA Department employee reacted to this situation by saying, "Basically sometimes you are just comparing two numbers that have nothing to do with reality. Of course nobody cares what the result of the comparison is, because it is nonsense."[15]

The HTA Department had even less influence on decision-makers in ministries. A former NHIF employee saw the HTA Department's impact as negligible. "Generally, the government decisions are so centralised and so hierarchical that the information [from the HTA Department] is not valuable in terms of [evidence-based] decisionmaking."[3] Other interviewees pointed out that the influence of the HTA Department was constrained by political considerations that top-level decisionmakers were sometimes inclined to prioritise over HTA. A former NHIF official elaborated, "the final decision is made by politically influenced stakeholders who absolutely do not understand this way of analysing drugs. There is a gap and this gap is quite huge. (...) There is a need for a stronger relationship between HTA and decisions." [16] Reimbursement procedures and the related timeline of decisions are 
only transparent until a certain point. Once ministerial bodies (e.g. state secretary of health or Ministry of Finance) got involved very frequently their opinions drove decisions and delayed announcements on reimbursement status. "Timelines are not transparent in the governmental sector. The fact that the Ministry of Finance has such a significant influence on the reimbursement of health technologies blocks constantly the planned timelines and the deadlines that should be maintained throughout the entire reimbursement decision-making process." [8]

In addition to factors constraining the HTA's influence in relation to the NHIF and the Ministry of Health, the influence of the HTA department was undermined by problems pertaining to its organisational capacity. A NHIF official stressed, "The HTA Department currently does not have the capacity to become a prominent body in the technology assessment."[13] There are approximately 80-100 submissions on pharmaceuticals and a similar number on medical devices per year. There are 13-15 permanent employees who work on evaluating the submissions and representing the HTA body in committees. The impact of these organisational constraints was exacerbated by the tight timelines imposed by the reimbursement legislation. A former HTA Department employee stated: "The 43 days for evaluation (...) does not make sense."[23] A former senior officer at HTA Department explained that the time-window also includes holidays, and therefore it "actually becomes 30 days of evaluation that is done by one health economist and one medical expert, who have more submissions in parallel."[20]

Human resource considerations were even more critical because of revolving door between the HTA Department and manufacturers and consultancies. A former HTA Department employee explained, "the biggest barrier of the development lof the Department] is the high fluctuation. (...) The entire staff (...) changed in the last 3.5 years. There is no continuity at the institution."[23] A key factor in this brain drain from the HTA Department was the low level of remuneration given the high level of skills and expertise of its employees. A consultancy employee pointed out the usual career path of young health economists: "people start their career at the public sector, work there for four-five years and then go to manufacturers or 
consultancies." [15] A NHIF employee described this process as "unfortunately the HTA Department works as a spring board for young people." [13]

Yet low salaries were only one reason for the outflow of highly qualified personnel. Many interviewees stressed that the limited influence on the reimbursement system can also contribute to decisions to move to the private sector. As a former NHIF employee pointed out, "they [HTA Department employees] also understand that it is not only about money, but what they do is essentially without impact on the final decision. It results a huge frustration."[3] A former HTA Department employee criticised the system as "You are in a job where you compare two numbers and nobody cares about it." [15]

Finally, there was also evidence of a vicious cycle whereby the HTA Department's limited impact on the reimbursement process encouraged actions by other stakeholders that further diminished its influence. This was perhaps best illustrated by the persistent low quality of manufacturers' HTA submissions. A HTA department employee explained that "people who worked in the HTA Department now work for pharma. They saw no impact, so they don't want to create a normal dossier."[17] Similarly, a former NHIF employee noted that "If someone would take the real decisions based on HTA submissions [by manufacturers], then the HTA submissions would have been revised and rethought years before. At the level of real decisions, [the decision-makers] are not interested in the HTA submission. That is why the HTA submissions are not for decision-making but for themselves. "[16] However, there were other reasons behind the low quality of submissions, including limited data availability. As a representative of academia emphasised, "Source of valid information is an important challenge for the HTA submission. Manufacturers, consultants and the governmental sector including the HTA Department do not necessarily use the same source for data."[8]

\subsection{Perceived costs and benefits of the HTA system}

Although the HTA Department has limited perceived influence on the reimbursement process, it still provided many important benefits. Given the lack of available data from HTA dossiers, appraisal documents by the HTA Department, or 
price negotiation contracts between the NHIF and manufacturers, it is not currently possible to express these benefits in monetary terms. Nevertheless, it was clear that the HTA Department was seen as creating many important intangible benefits for the Hungarian health policy in the long-run. These spillover benefits were most commonly associated with developing experience in applying HTA principles in policymaking, including awareness of their practical advantages and disadvantages. A senior manufacturer employee maintained, "There was "hurrah-optimism" at the beginning [HTA implementation in Hungary], but this is over. We realised how and what can be used from an HTA system. And we also know what the HTA system is not useable for."[6] Consequently, even senior NHIF officials ignored some of the recommendations coming from the HTA Department but they still relied on the principles of HTA in developing health policy. Ministerial policymakers tended to be even more strategic in this regard, showcasing HTA as a key achievement in building an evidence-based policymaking infrastructure. A former high-ranking NHIF employee emphasised, "We can tell the world that we have a good HTA system."[16]

A key specific benefit achieved by the HTA Department was the institutionalisation of explicit criteria for evaluating health technologies. A HTA consultant explained, "It is good that there is a platform to consider cost-effectiveness."[10] A former key HTA Department official stressed, "at least someone sits down at some point, thinks about, reads and evaluates the report about the technology. And this is forwarded to the decision-makers." [20] This was associated with curtailing informal influence wielded by economically powerful players such as drug companies. A former highlevel governmental official recalled, "Before the establishment of HTA system there was a "free-robbery" by companies. Before [the introduction of HTA in] 2004, pharma companies did whatever they wanted."[1] This has changed dramatically thanks to the operation of the HTA Department and the requirement to submit HTA dossiers. An academic reported, "It is very rare that someone wants to receive reimbursement based only on lobbying." [8]

Last but not least, the HTA Department underpinned a broader HTA system, including a range of educational activities unparalleled in the CEE region. As an 
academic expounded, "We have a HTA agency and many trained HTA experts in Hungary, which is unique in the region. There is an opportunity to study [HTA] in a post-graduate program without leaving the country."[14] In particular, the HTA Department was a key element of the infrastructure allowing for participation in international collaborations. A former HTA Department official stressed, "the Department was successful in joining to international programs and teams. This results in more experience."[20]

Notwithstanding the benefits of the HTA system in its current form, our interviewees also pointed out its costs. Overall, public resources spent on the Hungarian HTA system are considered to be negligible and the direct costs of the HTA system are mainly borne by manufacturers. From the manufacturer's perspective, a key cost associated with the current form of the appraisal process led by the HTA Department is the administrative fee for each reimbursement submission, amounting to $1,500,000$ HUF (approximately $€ 5,000$ ) per reimbursement application for pharmaceuticals, and 700,000 HUF (approximately $€ 2,300$ ) for simple medical devices.

Estimating the public costs associated with running the HTA Department proves more difficult. First, administrative fees levied on drug companies are shared between the NHIF and the HTA Department, based on an agreement whose details are not publicly disclosed. According to a senior NHIF employee, "[the share from the fee] is based on a contract between the organisations. So there is no need for case-by-case negotiation." [12] It is estimated that the HTA Department receives 80 percent of the fee for pharmaceuticals and 30 percent of the fee for simple medical devices. The HTA Department also has some external funding, for instance grants from the European network for Health Technology Assessment (EUnetHTA). The HTA Department's annual budget then according to these estimates should be between $€ 400,000$ and $€ 450,000$. However, since the operational costs of the Department are not separated from the cost of the NIPN, to which the HTA Department belongs, it is not clear whether the revenue generated from 
administrative fees plus income from externally funded projects is sufficient to cover its running costs.

An additional cost, from the manufacturers' perspective, is incurred by having to develop HTA submissions, a task commonly outsourced to external consultancy companies. While the prices of developing submissions are not publicly available, the average price mentioned by most interviewees was around $€ 10,000$, with the lowest limit of about $€ 4,000$. According to a manufacturing company's representative, referring to a general submission, "For this cost they [consultants] collect the input data for the [health economic] model. (...) Then they evaluate the results, make the sensitivity analysis and prepare all the required appendix or attachments." [9] New health economic models for economic evaluation are rarely developed for Hungarian submissions; in most cases global models are adopted to the Hungarian context. Prices of consultancies may increase if a new model needs to be developed, local data collection from primary sources is required, or if consultations with experts or additional studies such as systematic reviews are needed. In such cases, a very complex submission is typically priced at around $€ 35,000-€ 45,000$.

Estimating the total annual cost of developing HTA submissions by the pharmaceutical industry is challenging. A reasonably reliable method considers official yearly revenues of 3-4 major consultancies that focus on developing HTA submissions. There are also a handful of smaller companies with negligible annual revenue compared to the size of the consultancy market. Calculated this way, the consultancy market can be estimated to be around $€ 3,000,000-€ 3,500,000$. While this figure is likely to overestimate the market size (the consultancy firms may still provide other services not related to HTA), it was recognised as a reasonable estimate by a number of interviewees familiar with the sector.

As the perceived benefits of the HTA system were intangible and its costs were difficult to estimate, some interviewees maintained that public and private money spent on the system did not represent good value. This was evident given the low 
adherence of decision-makers to HTA recommendations. A high level government official explained, "Currently the importance and the role of the technology assessment disappears quickly from the system. So we could say that funds spent on this process are wasted money." [19] A former NHIF employee criticised the system by saying that early developments should not be the only perceived values anymore: "HTA moved the system from pre-historic stage to (...) an Anno Domini stage. But that it is. And how long can you be grateful to this?"[3]

Some interviewees noted that, even if manufacturers have to bear administrative costs and the costs of consultancies, the most important beneficiary is still the private rather than the public sector. Other interviewees pointed out that this system has only one clear winner, the consultancy sector. A representative of a consultant company pointed out that "benefits are there for all the consultants who are doing the [HTA] dossier[s]." [16]

Yet the perceived balance of costs and benefits could be altered by very recent policy changes, including a formal review of the methodological guideline for economic evaluation to better reflect the needs of the decision-maker, improve the skills of HTA Department workers in the validation of health economic models, build an international network and initiate direct communication to manufacturers. A former HTA Department employee explained, "It is not the worst system in the world. But it would be so easy to improve it. (...) We just need to write a few additional legal texts here and there, and we would have a much more efficient and transparent system."[15]

\section{Discussion and conclusion}

Our findings show that even if an HTA body fulfills its intended formal role of supporting evidence-based policymaking, it may face major institutional constraints. Based on the Hungarian case, its contributions to the pricing and reimbursement process can, for example be limited to its earliest phases, without considering subsequent contributions (e.g. involvement in pricing negotiations or revision procedures). We also found that the perceived influence of an HTA body on the 
reimbursement process may be limited, indicated by its inferior position in relationships with payers and health policymakers. Despite calls for increased openness of HTA as one of the founding principles of the field, in practice HTA can be associated with limited transparency and insufficient consultation with experts, manufacturers and patient organisations. Similar results were found in a recent overview on the HTA implementation in Hungary (Németh et al., 2017). This raises obvious normative concerns and may, as in Hungary, contribute to a further diminishing of the HTA body's role in pricing and reimbursement decision-making.

Our findings from the Hungarian case also suggest that an HTA body may have a positive impact on the development of a broader HTA system in a country, by laying the foundational infrastructure of evidence-based policymaking in healthcare and promoting an understanding of internationally accepted HTA principles (Voko et al. 2016). While costs and benefits of the Hungarian HTA system were difficult to quantify, there was strong scepticism as to whether it represented "good value for money". It is quite unusual that none of our interviewees mentioned financial or health benefits of the HTA system, as the benefits of HTA are typically thought of in monetary terms or savings and a more rational use of resources. A reason for this can be the methodological challenge of estimating the benefits of HTA for populations or health systems (Löblová, 2017). Some attempts have been made previously (Zechmeister and Schumacher 2012; Schumacher and Zechmeister 2013; Jacob and McGregor 1997). However, these studies relied mainly on published HTA reports and other related documents that were not available in our case. Yet more plausibly, we can attribute this non-finding to the lack of influence the Hungarian HTA Department has on eventual reimbursement decisions.

More fundamentally, despite the shared diagnosis of the major drawbacks of the HTA process, including the lack of access to actual prices, lack of transparency or capacity limitations at the HTA Department, none of the major stakeholders seemed to have a sufficient interest in initiating substantive reforms. To begin with, consulting companies have a stable and predictable market where competition is low due to the small number of established companies. Manufacturers' submissions 
for HTA evaluation create the basis for their business operations and their service portfolio can be diversified with HTA-related activities. Their human resource capacity is ensured by the education system and by the underpaid but experienced governmental officers from the HTA Department or from the NHIF. Manufacturers, on the other hand, seemed to have considered HTA as a tick-the-box exercise and therefore were willing to bear the associated costs, which seems to be minor from their perspective. These costs are predictable and rely heavily on consulting companies. Manufacturers understand that relevant questions of reimbursement are not discussed at the level of the HTA Department, but rather at the NHIF through price negotiations, or at a higher, health policy level, which is neither transparent nor predictable. Moving on to the national payer although it considered the opinion of HTA Department, it did not fully utilise the HTA submissions and the related appraisals in its decision-making. The NHIF has a monopolistic position during price negotiation with manufacturers. This gives it great bargaining power and it is not willing to share any information with other parties. Although the concept of HTA is accepted by the NHIF, there is no intention to utilise HTA to take account of changing circumstances, such as new evidence on effectiveness or costs. Further, HTA as a policy practice was poorly understood, which could be a key reason for a lack of concrete proposals to increase transparency or strengthen the evidence base for decisions. Finally, the voice of the academic sector was constrained by its limited involvement in compiling HTA dossiers, and patient organisations played no role in the HTA process.

On balance, our findings suggest that the HTA Department was the only stakeholder with an interest in realising the potential of the Hungarian HTA system. This echoes similar findings from other CEE countries by AUTHOR (Author forthcoming). Recent initiatives by the Department, such as renewing its methodological guidelines or increasing international collaboration through EUnetHTA were noted by other stakeholders. However, limited staffing, a substantial brain drain on the industry, time-pressure on submissions and huge workloads are significant barriers to achieving a stronger role in the reimbursement process. The current organisational structure, with the Department embedded in the NIPN, responsible for regulatory 
affairs, provides many opportunities for the HTA Department to achieve greater prominence. This could mirror a similar partnership between the European Medicines Agency and EUnetHTA at the EU level (Berntgen et al. 2014).

From a regional perspective, HTA in Hungary can be compared with that of Poland. The organisational and legal framework of the Polish Agency for Health Technology Assessment (AHTAPol) were also established after joining the EU, in 2004. The political significance of AHTAPol recommendations in the reimbursement process was reported to be important and their support is vital for legitimising reimbursement decisions (Ozieranski et al. 2012a; Ozieranski and King, 2016). HTA recommendations are publicly available from AHTAPol's website, and therefore HTA activities can be monitored and compared to reimbursement decisions to gain more understanding on potential influence of AHTAPol (Bochenek et al., 2017; Kolasa et al. 2011b). Further, the availability of HTA assessment reports, albeit frequently heavily redacted, makes it possible to investigate the role of various considerations (e.g. recommendations of other HTA bodies) in the recommendation by AHTAPol (Kolasa et al. 2011a). Similar studies would be highly welcomed in Hungary but the lack of relevant publicly available data makes them impossible. In addition, the public availability of HTA recommendations would make it possible to quantify their impact on subsequent reimbursement decisions, as has been done in Poland recently (Kawalec and Malinowski 2016). Notably, these new findings point to a lower policy impact than suggested by assessments made by stakeholders (Ozieranski et al. 2012a; Ozieranski et al. 2012b). Another similarity between the two countries was the extensive movement of staff from HTA bodies to private sector firms (Ozieranski and King, 2017. Forthcoming).

While many of our findings are specific to the Hungarian context, there are others from which lessons can be extrapolated across jurisdictions especially for those that are currently implementing or reforming their own HTA systems. A recent stakeholder analysis from Chile, for instance, revealed that Chilean stakeholders are aware of many potential shortcomings of an HTA body although there is a consensus on the need for such a body (Lavín et al. 2017). In particular, they are 
concerned about the danger of creating an HTA body without meaningful impact on policy. As the Hungarian example shows, this can happen because of bureaucratic turf wars between institutions, understaffing, or brain drain to the private sector. Our findings are also relevant to those countries where capacity building is seen as a crucial step in improving their HTA systems such as Croatia, Greece, Slovenia (Huic et al. 2017; Kani et al. 2017; Rupel, 2017). Without downplaying the efforts to increase human capacities, the Hungarian case suggests that creating large numbers of HTA experts may not be sufficient to build effective HTA institutions if these experts are drawn into the private sector after gaining experience. This means that countries with less competitive public sector salaries should pay attention to retention of staff in addition to recruitment and training. The Hungarian example also highlights the risk, also affecting some high-income countries, of creating a powerless institution which will, ten years later, face a reform stalemate and act as a tick-the-box bureaucratic exercise while stakeholders accept its costs without utilising its outputs. Finally, our observed benefits of training substantial numbers of HTA experts and promoting the culture of evidence-based policymaking are also likely to be replicated in other countries, and should be considered by countries considering HTA.

Two key weaknesses of our study must be mentioned. First, as suggested above, given the non-existence of publicly available documents on HTA and our lack of access to internal documents, we were unable to corroborate our qualitative data with primary sources (such as manufacturers' submissions or appraisal reports by the HTA Department, as well as their impact on final reimbursement decisions). Ideally, if documents related to HTA become publicly available, we would be able to triangulate some of our findings. This would most importantly involve comparing the HTA Department's opinions with reimbursement decisions at NHIF or at the ministerial level. In the absence of documentary data, we triangulated information by verifying it with multiple stakeholder groups. Second, since we were unable to reach representatives of clinicians, their perspective on the Hungarian HTA system was inferred by those interviewees who had experience collaborating with them. A key policy implication arising from these findings is that the Hungarian HTA system 
must review whether the reimbursement process requires strengthening the formal role of the HTA Department. We believe that studies on manufacturers' submissions and appraisal reports by the HTA Department are vital to answering this question. A first step towards a comprehensive review of the Hungarian HTA system depends on policymakers, as it involves increasing the transparency of the process. 


\section{References}

Banta, D. (2003). 'The development of health technology assessment', Health Policy, 63: 121-32.

Berntgen, M., A. Gourvil, M. Pavlovic, W. Goettsch, H. G. Eichler, and F. B. Kristensen. (2014). 'Improving the contribution of regulatory assessment reports to health technology assessments--a collaboration between the European Medicines Agency and the European network for Health Technology Assessment', Value Health, 17: 634-41.

Bochenek, T., E. Kocot, M. Rodzinka, B. Godman, K. Maciejewska, S. Kamal, and A. Pilc. (2016). 'The transparency of published health technology assessment-based recommendations on pharmaceutical reimbursement in Poland', Expert Rev Pharmacoecon Outcomes Res: 1-16.

Böhm K, Landwehr C, Steiner N. (2014). What explains "generosity" in the public financing of high-tech drugs? An empirical investigation of 25 OECD countries and 11 controversial drugs. J Eur Soc Policy, 24: 39-55.

Boncz I, Dozsa C, Kalo Z, Nagy L, Borcsek B, Brandtmuller A, Betlehem J, Sebestyen A, Gulacsi L. Development of health economics in Hungary between 1990-2006. Eur J Health Econ. 2006; 7(S1):4-6.

Endrei, D., B. Molics, and I. Agoston. (2014). 'Multicriteria decision analysis in the reimbursement of new medical technologies: real-world experiences from Hungary', Value Health, 17: 487-9.

Fischer KE, Rogowski WH, Leidl R, Stollenwerk B. (2013). Transparency vs. closeddoor policy: Do process characteristics have an impact on the outcomes of coverage decisions? A statistical analysis. Health Policy, 112: 187-96.

Guest, GS., KM. MacQueen, and Namey EE. (2011). 'Applied Thematic Analysis'. SAGE Publications.

Gulacsi L, Boncz I, Drummond M. Issues for countries considering introducing the „fourth hurdle”: The case of Hungary. Int J Technol Assess Health Care. 2004; 20(3): 337-341.

Gulácsi, L., V. Brodszky, M. Pentek, S. Varga, G. Vas, and I. Boncz. (2009). 'History of health technology assessment in Hungary', Int J Technol Assess Health Care, 25 Suppl 1: 120-6.

Gulácsi, L., and M. Pentek. (2014). 'HTA in Central and Eastern European countries; the 2001: A Space Odyssey and efficiency gain', Eur J Health Econ, 15: 675-80. 
Gulácsi, L., A. M. Rotar, M. Niewada, O. Löblová, F. Rencz, G. Petrova, I. Boncz, and N. S. Klazinga. (2014). 'Health technology assessment in Poland, the Czech Republic, Hungary, Romania and Bulgaria', Eur J Health Econ, 15 Suppl 1: S13-25.

Henshall, C., W. Oortwijn, A. Stevens, A. Granados, and D. Banta. (1997). 'Priority setting for health technology assessment. Theoretical considerations and practical approaches. Priority setting Subgroup of the EUR-ASSESS Project', Int J Technol Assess Health Care, 13: 144-85.

Huic M, Tandara Hacek R, Svajger I. (2017) 'Health technology assessment in Central, Eastern and South European countries: Croatia', Int J Technol Assess Health Care. 2017 Aug 14:1-8.

Inotai, A., M. Pekli, G. Jona, O. Nagy, E. Remak, and Z. Kaló. (2012). 'Attempt to increase the transparency of fourth hurdle implementation in Central-Eastern European middle income countries: publication of the critical appraisal methodology', BMC Health Serv Res, 12: 332.

Jacob, R., and M. McGregor. (1997). 'Assessing the impact of health technology assessment', Int J Technol Assess Health Care, 13: 68-80.

Kaló, Z., J. Bodrogi, I. Boncz, C. Dózsa, G. Jóna, R. Kövi, Z. Pásztélyi, and B. Sinkovits. (2013). 'Capacity Building for HTA Implementation in Middle-Income Countries: The Case of Hungary.', Value in Health Regional Issues, 2: 264-66.

Kaló, Z., A. Gheorghe, M. Huic, M. Csanadi, and F. B. Kristensen. (2016). 'HTA Implementation Roadmap in Central and Eastern European Countries', Health Econ, 25 Suppl 1: 179-92.

Kani C, Kourafalos V, Litsa P (2017). 'Current environment for introducing health technology assessment in Greece', Int J Technol Assess Health Care. 2017 Jul 31:1-6.

Kawalec, P., and K. P. Malinowski. (2016). 'Relating Health Technology Assessment recommendations and reimbursement decisions in Poland in years 2012-2014, a retrospective analysis', Health Policy. Vol. 120, Issue 11: 1240-1248

Kolasa, K., M. Dziomdziora, and L. Fajutrao. (2011a). 'What aspects of the health technology assessment process recommended by international health technology assessment agencies received the most attention in Poland in 2008?', Int J Technol Assess Health Care, 27: 84-94.

Kolasa, K., Z. Kaló, and V. Zah. (2016). 'The use of non-economic criteria in pricing and reimbursement decisions in Central and Eastern Europe: issues, trends and recommendations', Expert Rev Pharmacoecon Outcomes Res, 16: 483-8.

Kolasa, K., Z. Kaló, V. Zah, and T. Dolezal. (2012). 'Role of health technology assessment in the process of implementation of the EU Transparency Directive: 
relevant experience from Central Eastern European countries', Expert Rev Pharmacoecon Outcomes Res, 12: 283-7.

Kolasa, K., S. Schubert, A. Manca, and T. Hermanowski. (2011b). 'A review of Health Technology Assessment (HTA) recommendations for drug therapies issued between 2007 and 2009 and their impact on policymaking processes in Poland', Health Policy, 102: 145-51.

Landwehr C, Boehm K. (2011). 'Delegation and Institutional Design in Health-Care Rationing', Governance, 24: 665-88.

Lavín CP, Alaniz R, Espinoza M. (2017). 'Visions of stakeholders about instutionalization of health technology assessment in Chile: A qualitative study', Int J Technol Assess Health Care, Jun 9:1-4.

Löblová, O. (2017). 'What has health technology assessment ever done for us?', Journal of Health Services Research \& Policy, 1355819617725545.

Löblová, O. (2016). 'Three worlds of health technology assessment: explaining patterns of diffusion of HTA agencies in Europe', Health Econ Policy Law, 11(3):25373.

Mandrik, O., S. Knies, Z. Kaló, and J. L. Severens. (2015). 'Reviewing transferability in economic evaluations originating from Eastern Europe', Int J Technol Assess Health Care, 31: 434-41.

Németh B, Csanádi M, Kaló Z. (2017) Overview on the Current Implementation of Health Technology Assessment in the Healthcare System in Hungary. Int J Technol Assess Health Care 1-6. 2017 Apr 24.

Oortwijn, W. J., S. R. Hanney, A. Ligtvoet, S. Hoorens, S. Wooding, J. Grant, M. J. Buxton, and L. M. Bouter. (2008). 'Assessing the impact of health technology assessment in The Netherlands', Int J Technol Assess Health Care, 24: 259-69.

Ozieranski, P., and L. King. (2016). 'The persistence of cliques in the post-communist state. The case of deniability in drug reimbursement policy in Poland', Br J Sociol, 67: 216-41.

Ozieranski, P., M. McKee, and L. King. (2012a). 'Pharmaceutical lobbying under postcommunism: universal or country-specific methods of securing state drug reimbursement in Poland?', Health Econ Policy Law, 7: 175-95.

Ozieranski, P., M. McKee, and L. King. (2012b). 'The politics of health technology assessment in Poland', Health Policy, 108: 178-93. 
Ozieranski, P. and L King. 2017. Forthcoming. 'Governing drug reimbursement policy in Poland: The role of the state, civil society and the private sector.' Theory and society.

Rupel PV. (2017). 'Current implementation of health technology assessment in healthcare system in Slovenia', Int J Technol Assess Health Care. 2017 Apr 24:1-5.

Schumacher, I., and I. Zechmeister. (2013). 'Assessing the impact of health technology assessment on the Austrian healthcare system', Int J Technol Assess Health Care, 29: 84-91.

Szende, Á., Z. Mogyorósy, N. Muszbek, J. Nagy, G. Pallos, and C. Dózsa. (2002). 'Methodological Guidelines for Conducting Economic Evaluation of Healthcare Interventions in Hungary: A Hungarian Proposal for Methodology Standards', The European Journal of Health Economics, 3: 196-206.

Valesco-Garrido., M, and R. Busse. (2005). 'Health technology assessment - An introduction to objectives, role of evidence, and structure in Europe', European Observatory on Health Systems and Policies.

Voko, Z., K. L. Cheung, J. Jozwiak-Hagymasy, S. Wolfenstetter, T. Jones, C. Munoz, S. M. Evers, M. Hiligsmann, H. de Vries, and S. Pokhrel. (2016). 'Similarities and differences between stakeholders' opinions on using Health Technology Assessment (HTA) information across five European countries: results from the EQUIPT survey', Health Res Policy Syst, 14: 38.

Yin, RK. (2003). 'Case Study Research: Design and Methods: (Applied Social Research Methods, Volume 5) '. SAGE Publications.

Zechmeister, I., and I. Schumacher. (2012). 'The impact of health technology assessment reports on decision making in Austria', Int J Technol Assess Health Care, 28: 77-84. 
Table 1. Categories of interviewees

\begin{tabular}{|c|c|c|c|}
\hline Organisation & $\begin{array}{l}\text { Number of } \\
\text { completed } \\
\text { interviews }\end{array}$ & $\begin{array}{l}\text { Refusals } \\
\text { and non- } \\
\text { responses }\end{array}$ & $\begin{array}{l}\text { Total } \\
\text { approached }\end{array}$ \\
\hline \multicolumn{4}{|c|}{ Public sector } \\
\hline $\begin{array}{l}\text { HTA Department and National } \\
\text { Institute of Pharmacy and Nutrition }\end{array}$ & 4 & 1 & 5 \\
\hline Ministry responsible for health & 3 & & 3 \\
\hline National Health Insurance Fund & 3 & 2 & 5 \\
\hline Academia & 3 & & 3 \\
\hline \multicolumn{4}{|c|}{ Private sector } \\
\hline Manufacturers & 5 & 1 & 6 \\
\hline Consulting companies & 5 & 1 & 6 \\
\hline \multicolumn{4}{|c|}{ Non-governmental organisations } \\
\hline Patient organisations & 3 & 0 & 3 \\
\hline Colleges of Medical Professionals & 0 & 2 & 2 \\
\hline Total & 26 & 7 & 33 \\
\hline
\end{tabular}

